\section{On copyright \\ Copyright in the networked world: digital legal deposit}

\author{
Michael Seadle
}

\section{The author}

Michael Seadle is Editor of Library Hi Tech. He is also Digital Services and Copyright Librarian at Michigan State University, East Lansing, MI, USA.

\section{Keywords}

Copyright, Publishing

\section{Abstract}

Legal deposit is the requirement that particular types of material be deposited with a national library or designated research libraries. US law does not at present include any requirement for the deposit of works that exist solely in the form of Web pages. For digital materials, it makes no sense to write rules for legal deposit based on the medium. Nations and national libraries that ignore legal deposit for digital works will find themselves missing a significant and unrecoverable portion of their cultural heritage.

\section{Electronic access}

The research register for this journal is available at http://www.mcbup.com/research_registers

The current issue and full text archive of this journal is available at

http://www.emerald-library.com/ft
At the Joint Conference on Digital Libraries (24-27 June) Adrienne Muir of Loughborough University in the UK presented a paper on legal deposit. She wrote:

The concept and practice of legal deposit is under threat in the digital environment. The main, though not the original, aim of legal deposit is to ensure the preservation of a nation's intellectual and cultural heritage over time. Many countries are extending legal deposit regulations to cover digital publications in order to maintain comprehensive national archives (Muir, 2001, p. 165).

Afterwards we discussed whether US law requires legal deposit for digital materials. I thought not, but after further research I now realize that, as with all things related to copyright, the issue is complicated. This column both attempts to correct my overly simple answer, and to examine some of the issues that Muir raised.

\section{What is legal deposit?}

Legal deposit is the requirement that particular types of material be deposited with a national library or designated research libraries. In the case of the USA, the Library of Congress (LC) receives all such materials.

Under the 1909 US copyright law, the requirement was relatively straightforward. Anyone who wanted copyright protection for a work had to register that work with the Copyright Office, and provide two copies of the work for deposit with LC. This meant that a large body of "gray literature" did not get deposited with LC, because the authors had no interest in copyright protection. This included everything from in-house corporate publications to newsletters by radical organizations more interested in dissemination than publication. But all protected works were deposited: no deposit, no protection.

This situation changed in 1978 when the new US copyright law went into effect - but not completely. US law extended automatic copyright protection to essentially all original works the moment they were fixed in permanent form, which could be as transient as saving to a computer disk. But the law also

The author is not a lawyer, and nothing in this column should be considered legal advice. 
created two levels of copyright protection, and reserved statutory damages to registered works (17 USC 412). In fact, anyone who wants to sue for copyright infringement under US law needs to register the work retrospectively before bringing suit, and registration still requires submitting two copies of most works to LC.

In general, large commercial print publishers continue to register works and continue to comply with legal deposit. It is probably reasonable to assume that over 90 percent of the titles in Books in Print have been deposited at LC. It is probably also reasonable to assume that 90 percent of the printed works that do not appear in Books in Print have no copies at LC. The point is, that legal deposit occurs irregularly even in the Gutenberg world.

\section{US requirements for digital legal deposit}

In her paper, Muir discusses a number of countries that have started to deal explicitly with legal deposit for digital materials. These include Canada, Australia, The Netherlands, Finland, and Sweden (Muir, 2001, p. 171). Some seem to be dealing primarily with digital works on CD-ROM and similar media. Others, including Canada, have addressed aspects of the more complex problem of the Internet.

Since the USA is probably still the largest producer of digital works, one of the key questions is whether existing US copyright law can be interpreted to include a requirement for the legal deposit of digital materials. If it does, then the issue is one of procedures and mechanisms. If not, then changes to the law would need to come first.

The language of the US copyright law does not specifically deny that legal deposit applies to all works, but it sets a time-requirement only for "published" works:

(a) Except as provided by subsection (c), and subject to the provisions of subsection (e), the owner of copyright or of the exclusive right of publication in a work published in the United States shall deposit, within three months after the date of such publication -

(1) two complete copies of the best edition; or

(2) if the work is a sound recording, two complete phonorecords of the best edition, together with any printed or other visually perceptible material published with such phonorecords. Neither the deposit requirements of this subsection nor the acquisition provisions of subsection (e) are conditions of copyright protection (17 USC 407).

It is interesting that the last phrase undercuts the mechanism by which legal deposit has traditionally been enforced, since it is not required for copyright protection. The US copyright office emphasizes the word "published" in its own explanation of "mandatory" deposit:

All works under copyright protection that are published in the United States are subject to the mandatory deposit provision of the copyright law (Copyright Office, Library of Congress 2000).

UNESCO's interpretation of US law sounds more sweeping, but also recognizes that publication is a key factor:

In the United States of America, all works under copyright protection published in the USA are subject to mandatory legal deposit, even if they do not contain a "notice of copyright". (That is to say that it is no longer the case that if the producer of a work does not wish to register it for copyright, there is no deposit requirement. Now, since copyright exists from the moment of creation of a work, all published works must be deposited, whether registered or not.) (UNESCO, 1997).

"Publication" is a troubling word, because it has a fairly precise legal meaning under US law, with exceptions that most non-lawyers find far from obvious. Here is the definition that the Copyright Office quotes:

Publication is defined in the copyright law as "the distribution of copies or phonorecords of a work to the public by sale or other transfer of ownership, or by rental, lease, or lending" (Copyright Office, Library of Congress, 2000).

The language suggests physical copies. Works distributed without physical copies do not fit the strict legal definition of publication. In talking about the development of its television collection, LC explains:

Because network television programs were not sold or leased in copies, there was considerable uncertainty as to when TV programs were "published" within the meaning of the existing copyright statute. Since the library's power to compel copyright holders to deposit copies extended only to "published" works, the mandatory deposit features of US copyright law were shown to be inadequate to the task of 
assuring the orderly development of a comprehensive TV archive (Flacks, 1985).

This distinction between published and unpublished works splits digital works into two arbitrary classes: those distributed on a physical medium, such as a CD-ROM, and those available only on the Internet, where no actual (legal) change of ownership takes place, even though thousands of transient copies may exist on computers around the world. The National Library of Australia (2001) recognizes this split in its description of the US situation:

In the United States mandatory deposit provisions are found in Section 407 of the Copyright Act of 1976. Through the Code of Federal Regulations, categories of materials can be exempted from deposit requirements. These Regulations originally exempted material published solely in machine readable form. This exemption was revoked in 1988 and deposit was then required of certain publicly available machine readable material. When CD-ROMs are deposited, the complete package is required: this includes all accompanying documentation including a printed version if it is available. Voluntary CD-ROM agreements stipulating how the Library can use deposited CD-ROMs were introduced in 1993. Mandatory deposit is not applied to online electronic works.

In other words, US Copyright law does include legal deposit for digital works that were published and distributed on physical media, where some orderly transfer of ownership for the copy took place, and where the ordinary two-copy deposit requirement can be made without serious procedural reinvention. It also presumably includes works, whether they meet the definition of "published" or not, that authors have troubled to register with the US Copyright Office. But the law does not at present include any requirement for the deposit of works that exist solely in the form of Web pages, though it could if the legal definition of the word "published" slipped suddenly from a Gutenberg into a Berners-Lee universe.

\section{What would it require?}

It may be just as well that the law had not caught up to Web-based publishing, since a number of copyright-related issues remain to solve. Most of these have to do with areas where no obvious analogy to print materials exists. Here are some examples.

\section{Nationality}

With a printed work, the publisher makes the nationality relatively clear on the title page (or its verso). There are complex situations with large presses where a book is published simultaneously in, say, Chicago and London (University of Chicago Press), or Oxford and New Delhi (Oxford University Press). The rule of thumb is that each country treats the work as a local publication. Prices, taxes, distribution mechanisms are all slightly different for the different lands.

Web-based publishing could follow a similar model by treating each server as the Internetequivalent of a publishing house, and there is some legal precedent for this, since judges cannot enforce rulings against servers in other countries. But servers are distribution mechanisms at least as much as they are publishers. This is particularly true of commercial Internet service providers, which will let anyone buy resource on their machines. Is a US mirror site for a German database a separate publication analogous to what University of Chicago Press and Oxford University Press do, or is it more like a relay station for a television broadcast, or is it just a local copy of a foreign publication much like the paperback copy of Die Schattenboxerin (Parei, 2001) that I brought home from Germany last May? The problem with mirror sites is that they do not generally behave differently from location to location, as multi-country print publications do. There are exceptions, of course. Some search engines have localizations for different countries, but then they are not true mirror sites.

\section{Versions}

Printed works can have multiple editions, but a relatively small portion of the titles published each year ever go into a second edition, while Web-pages can mutate on a daily, even an hourly basis. It is impossible to say what the authoritative version of my home page is, because I update it whenever I add a new project or get tired of the current color-scheme. When the 1978 copyright law was written, the legal requirement for fixing a work in 
permanent form implied a level of immutability. Even something written in pencil requires some effort to erase, and most people will grab a new piece of paper rather than attempt to rub out whole paragraphs.

One solution to the version problem is to take periodic snapshots of the Web, as does Brewster Kahle's Internet Archive[1], but this would lead to more duplication than most libraries would presently want to handle, and it would not guarantee all editions if a Web-page changed more than once between snapshots.

\section{Links}

Print publications are relatively self-contained. They have footnotes, which have been described as a form of pre-Web hyperlink, but no reader expects to see anything new after tapping on a printed footnote. Clicking on a Web-hyperlink is integral to the structure of Web-publication, especially since the link may not be to some external work, but to another page that intellectually belongs to the same work. For some works, it is relatively easy to define the boundary, but often it is not. For example, Michigan State University has published a number of separate works as part of "Shaping the values of youth: Sunday school books in nineteenth century America"[2]. The collection includes an introductory essay and essays about each genre. Is each book a separate digital publication, or is the whole a kind of collective work? And if it is a collective work, is the "American radicalism" collection on the same Web site integral or separate? These questions usually have obvious answers in print, but do not on the Web. The issue for legal deposit, of course, is: which linked materials get deposited? The links could lead anywhere and everywhere.

\section{Protections}

Some print works come with shrink-wrapped covers. Happily, those covers have no legal status in the copyright law, as do technological protections for digital works. The Digital Millennium Copyright Act made it a crime to break such protections in order to get access to a work, even for "fair use" (17 USC 107) purposes. The problem this presents for legal deposit is whether the work would be accessible to anyone after deposit. The access restrictions may depend on codes or addresses no longer in use. A work which is utterly inaccessible may as well not be deposited at all.

\section{Conclusion}

This is by no means an exhaustive list of the unsolved issues. Muir (2001) discussed many others, including: "identification of publications; selection; acquisition; accession and processing, including storing; preservation; and access" (p. 165). A number of countries are attempting to develop policies and procedures for handling the legal deposit of a broad range of digital materials. Major Internet-publishing countries like the USA, the UK, and Germany should do the same, because the problem will only grow in time.

For digital materials, it makes no sense to write rules for legal deposit based on the medium. Increasingly the medium on which a digital work exists matters less than what mark-up formats it uses, what external links it requires, and what technological protections it has. Nations and national libraries that ignore legal deposit for digital works will find themselves missing a significant and unrecoverable portion of their cultural heritage.

\section{Notes}

1 www.archive.org

2 http://digital.lib.msu.edu/ssb/

\section{References}

17 USC 107, United States Code, Title 17, Chapter 1, section 107, Available (July 2001): http:// www4.law.cornell.edu/uscode/17/107.html

17 USC 407, United States Code, Title 17, Chapter 4, section 407, Available (July 2001): http:// www4.law.cornell.edu/uscode/17/407.html

17 USC 412, United States Code, Title 17, Chapter 4, section 412, Available (July 2001): http:// www4.law.cornell.edu/uscode/17/412.html

Copyright Office, Library of Congress (2000), "Mandatory deposit of copies or phonorecords for the library of congress", August, Available (July 2001): http:// www.loc.gov/copyright/circs/circ07d.html 
Flacks, L. (1985), quoted in "Television in the library of congress", Library of Congress, November, Available (July 2001): http://www.loc.gov/rr/mopic/ tvcoll.html

Muir, A. (2001), "Legal deposit of digital publications: a review of research and development activity", Proceedings of First ACM/IEEE-CS Joint Conference on Digital Libraries, Roanoke, VA, 24-28 June, pp. $165-73$.
National Library of Australia (2001), "PADI: preserving access to digital information: legal deposit", ACT, Canberra, 1 July, Available (July 2001): http:// www.nla.gov.au/padi/topics/67.html\#US

Parei, I. (2001), Die Schattenboxerin, Fischer, Frankfurt am Main.

UNESCO (1997), "The legal deposit of electronic publications", 6 March, Available (June 2001): http:// www.unesco.org/webworld/memory/legaldep.htm 